\title{
Asparagine and Glutamine Side-Chains and Ladders in HET-s(218-289) Amyloid Fibrils Studied by Fast Magic-Angle Spinning NMR
}

\author{
Thomas Wiegand ${ }^{1 * t}$, Alexander A. Malär ${ }^{1 \dagger}$, Riccardo Cadalbert ${ }^{1}$, Matthias Ernst ${ }^{1}$, \\ Anja Böckmann ${ }^{2}$ and Beat H. Meier ${ }^{1 *}$
}

${ }^{1}$ Physical Chemistry, Eidgenössische Technische Hochschule (ETH) Zurich, Zurich, Switzerland, ${ }^{2}$ Molecular Microbiology and Structural Biochemistry, UMR 5086 CNRS/Université de Lyon, Labex Ecofect, Lyon, France

OPEN ACCESS

Edited by:

Mark Pfuhl,

King's College London,

United Kingdom

Reviewed by:

Johanna Becker-Baldus,

Goethe University Frankfurt, Germany

Steven Brown

University of Warwick,

United Kingdom

*Correspondence:

Thomas Wiegand

thomas.wiegand@phys.chem.ethz.ch

Beat H. Meier

beme@ethz.ch

${ }^{\dagger}$ These authors have contributed equally to this work

Specialty section:

This article was submitted to

Structural Biology,

a section of the journal

Frontiers in Molecular Biosciences

Received: 10 July 2020

Accepted: 28 August 2020

Published: 30 September 2020

Citation:

Wiegand T, Malär $A A$,

Cadalbert R, Ernst M, Böckmann A and Meier BH (2020) Asparagine

and Glutamine Side-Chains

and Ladders in HET-s(218-289)

Amyloid Fibrils Studied by Fast

Magic-Angle Spinning NMR.

Front. Mol. Biosci. 7:582033.

doi: 10.3389/fmolb.2020.582033
Asparagine and glutamine side-chains can form hydrogen-bonded ladders which contribute significantly to the stability of amyloid fibrils. We show, using the example of HET-s(218-289) fibrils, that the primary amide side-chain proton resonances can be detected in cross-polarization based solid-state NMR spectra at fast magic-angle spinning (MAS). J-coupling based experiments offer the possibility to distinguish them from backbone amide groups if the spin-echo lifetimes are long enough, which turned out to be the case for the glutamine side-chains, but not for the asparagine sidechains forming asparagine ladders. We explore the sensitivity of NMR observables to asparagine ladder formation. One of the two possible asparagine ladders in HET$\mathrm{s}(218-289)$, the one comprising N226 and N262, is assigned by proton-detected $3 \mathrm{D}$ experiments at fast MAS and significant de-shielding of one of the $\mathrm{NH}_{2}$ proton resonances indicative of hydrogen-bond formation is observed. Small rotating-frame ${ }^{15} \mathrm{~N}$ relaxation-rate constants point to rigidified asparagine side-chains in this ladder. The proton resonances are homogeneously broadened which could indicate chemical exchange, but is presently not fully understood. The second asparagine ladder (N243 and N279) in contrast remains more flexible.

Keywords: solid-state NMR, fast MAS, amyloid fibrils, hydrogen bond, asparagine ladder

\section{INTRODUCTION}

The terminal primary amide group of asparagine and glutamine side-chains can function as both, hydrogen-bond donor via the $\mathrm{NH}_{2}$ group as well as acceptor via the carbonyl group and thus these side-chains are important for protein stability (Vernet et al., 1995; Worth and Blundell, 2010), protein-protein (Van Melckebeke et al., 2010; Talavera et al., 2011; Wälti et al., 2016), protein-ligand (Higman et al., 2004; Raymond et al., 2004) and protein RNA/DNA interactions (Luscombe et al., 2001; Lejeune et al., 2005). In amyloids they can form asparagine/glutamine ladders (Wan and Stubbs, 2014; Riek and Eisenberg, 2016; Eisenberg and Sawaya, 2017; Kurt et al., 2017), e.g., in $\alpha$-synuclein (Guerrero-Ferreira et al., 2018, 2019), A $\beta(1-42)$ (Colvin et al., 2016; Wälti et al., 2016), the functional amyloid HET-s(218-289) (Wasmer et al., 2008; Van Melckebeke et al., 2010), and the polyglutamine rich Orb2 (Hervas et al., 2020) (for some 
representative structures see Figure 1 and Supplementary Figure S1). Such side-chains play also important roles in many other amyloids, including the yeast prion Sup35 (Luckgei et al., 2013), huntingtin (Hoop et al., 2016), and prions (Kurt et al., 2017), where these residues form the fibril core, ladders and steric zippers (Sawaya et al., 2007).

Solid-state nuclear magnetic resonance (NMR) spectroscopy is a suitable technique to identify asparagine/glutamine ladders in amyloid fibrils: the ${ }^{1} \mathrm{H}$ chemical-shifts are sensitive reporters and less-shielded ${ }^{1} \mathrm{H}$ resonances indicate a participation of the proton in a hydrogen bond (Wagner et al., 1983) whereas relaxation properties can describe dynamical effects. Such spectroscopic information extends the structure information from NMR and cryo-EM (Gremer et al., 2017; Guerrero-Ferreira et al., 2018, 2019; Kollmer et al., 2019; Schmidt et al., 2019; Hervas et al., 2020). Infrared spectroscopy (IR) has also been used recently to identify glutamine ladders in amyloid-forming peptides ( $\mathrm{Wu}$ et al., 2019) and solution-state NMR has been used to probe asparagine side-chain properties engaged in a dense hydrogenbond network in the leucine-rich repeat (LRR) proteins pp32 (Klein et al., 2019) (see also Figure 1D). The detection of glutamine and asparagine side-chains by solution-state NMR spectroscopy, e.g., in ${ }^{15} \mathrm{~N},{ }^{1} \mathrm{H}$ HSQC-type experiments, has been employed in a variety of biological contexts to probe their structural and dynamic properties (Buck et al., 1995; Vance et al., 1997; Cai et al., 2001; Mulder et al., 2001; Higman

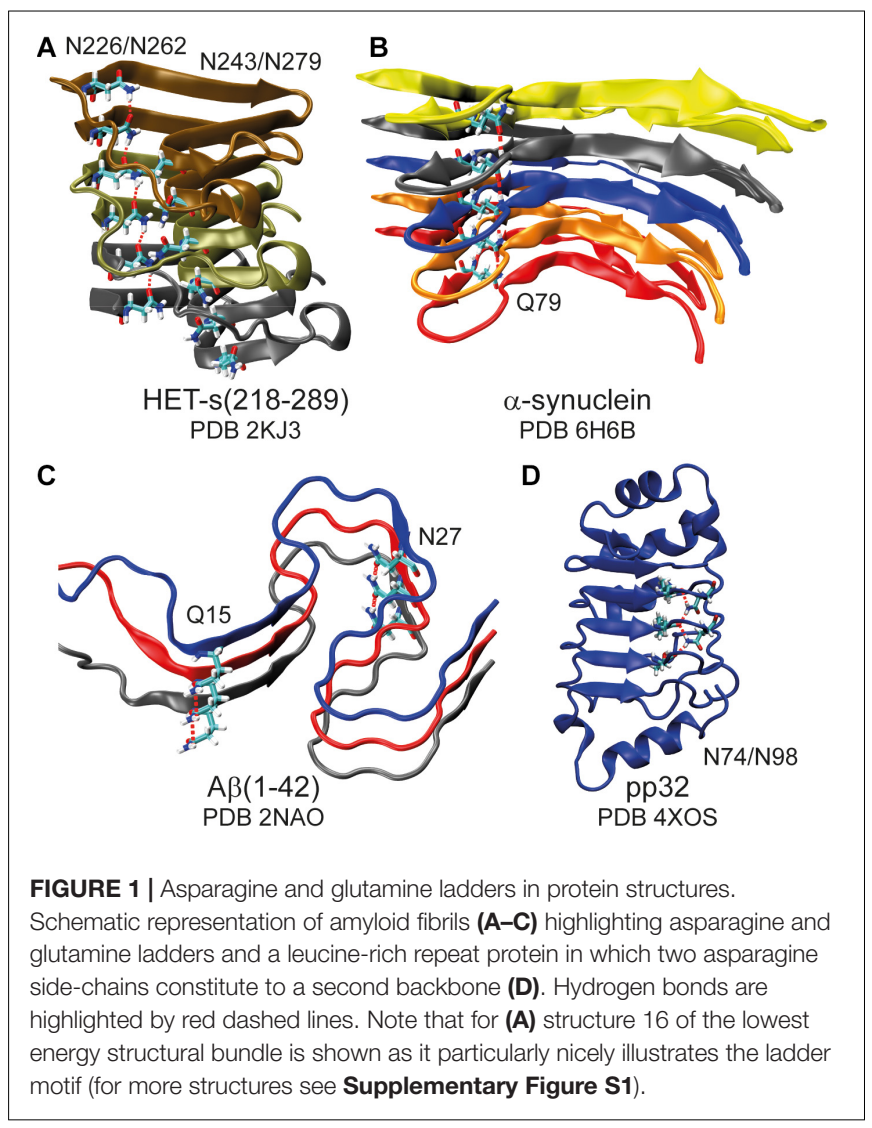

et al., 2004; Klein et al., 2019). We show that fast magicangle spinning (MAS) (Agarwal et al., 2014; Andreas et al., 2015, 2016; Böckmann et al., 2015; Sternberg et al., 2018; Stöppler et al., 2018; Malär et al., 2019; Penzel et al., 2019; Vasa et al., 2019) can detect asparagine and glutamine side-chains in cross-polarization (CP) solid-state NMR proton spectra and, sometimes, also in $J$-coupling based experiments, in particular INEPT (Morris and Freeman, 1979) experiments, which then can be employed to distinguish the two $\mathrm{NH}_{2}$ side-chain proton resonances from amide $\mathrm{NH}$ protons. In amyloid fibrils of HETs(218-289) of the filamentous fungus Podospora anserina, the asparagine side-chains are visible in CP-based experiments, but not in INEPT experiments at an MAS frequency of $110 \mathrm{kHz}$. We discuss NMR spectral and relaxation parameters determined for asparagine side-chains forming asparagine ladders, such as highfrequency shifted proton resonances and small rotating-frame ${ }^{15} \mathrm{~N}$ relaxation-rate constants.

\section{RESULTS AND DISCUSSION}

\section{Assignment of Asparagine and Glutamine Residues in HET-s(218-289)}

The side-chain amide protons of asparagine (N) and glutamine (Q) side-chains can be observed in proton-detected fast MAS experiments. $\mathrm{CP}$ hNH correlation spectra of deuterated and $100 \%$ back-exchanged, as well as uniformly ${ }^{13} \mathrm{C}$ and ${ }^{15} \mathrm{~N}$ labeled HET-s(218-289) fibrils (abbreviated in the following with DUL), recorded at a MAS frequency of $110 \mathrm{kHz}$, are shown in Figure 2A. N/Q side-chains resonate in a region somewhat more shielded than backbone amides for both ${ }^{15} \mathrm{~N}$ and ${ }^{1} \mathrm{H}$ shifts although the regions overlap. Some of the observed N/Q side-chains (e.g., Q240, N226, N262) lead to two proton correlation peaks with a common ${ }^{15} \mathrm{~N}$ frequency indicating no or only a slow rotation around the $\mathrm{C}^{\gamma}-\mathrm{N}^{\delta 2}(\mathrm{~N})$ or $\mathrm{C}^{\delta}-\mathrm{N}^{\varepsilon 2}(\mathrm{Q})$ bond as shown in solution-state experiments (Guenneugues et al., 1997). The side-chain assignment is based on a NCOCX 3D experiment performed on a fully protonated HET-s(218-289) sample shown in Supplementary Figure $\mathbf{S 2}$ which yields the ${ }^{15} \mathrm{~N}$ side-chain resonances. The proton chemical-shift values are extracted from the $2 \mathrm{D}$ hNH spectrum (Figure 2A). In total, four out of five asparagine side-chains (N226, N243, N262, N279) and the two glutamine side-chains (Q240, Q259) were identified in the hNH spectrum, only the very C-terminal N289 remains absent probably due to large dynamics (Van Melckebeke et al., 2010). The side-chains of N243, Q259 and N279 have however lower intensity (Supplementary Figure S3 for signal-to-noise ratios extracted from 2D spectra) and remain undetected in protondetected $3 \mathrm{D}$ spectra and thus only one $\mathrm{NH}_{2}$ proton is assigned for $\mathrm{N} 243$ and N279. Note that the second $\mathrm{NH}_{2}$ resonance of Q259 is not visible in the CP spectrum, but can be identified in an INEPT-based hNH spectrum (vide infra).

We next address the question whether J-coupling based INEPT-hNH experiments are also suitable to detect N/Q sidechains, similar to ${ }^{15} \mathrm{~N},{ }^{1} \mathrm{H}$ HSQC experiments applied in solutionstate NMR. The well-known differences in the magnetizationtransfer curves of $\mathrm{NH}$ and $\mathrm{NH}_{2}$ side-chain resonances in a 


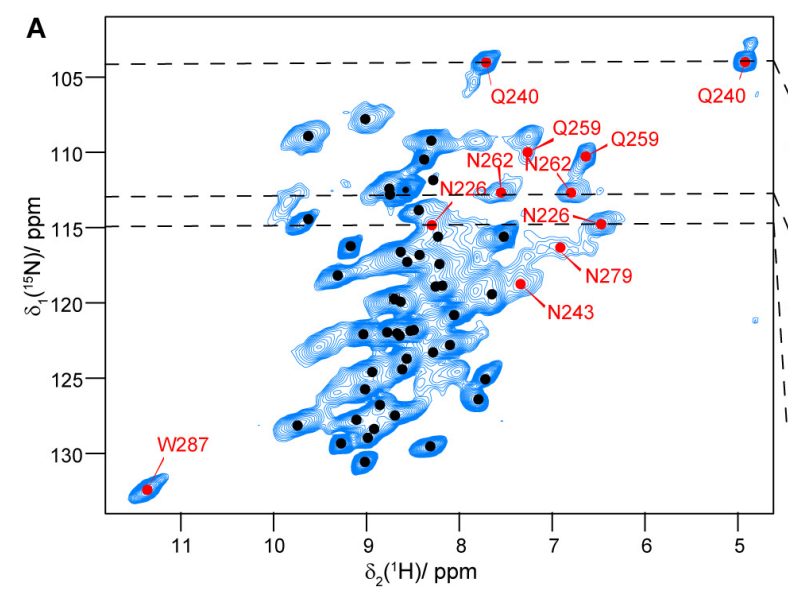

B<smiles>CCCC(=O)N(C)CCOC(=O)N([Hg])CCC</smiles>

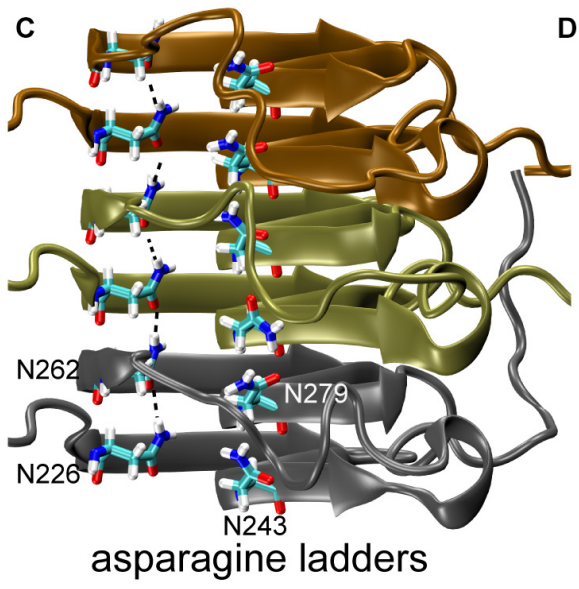

D
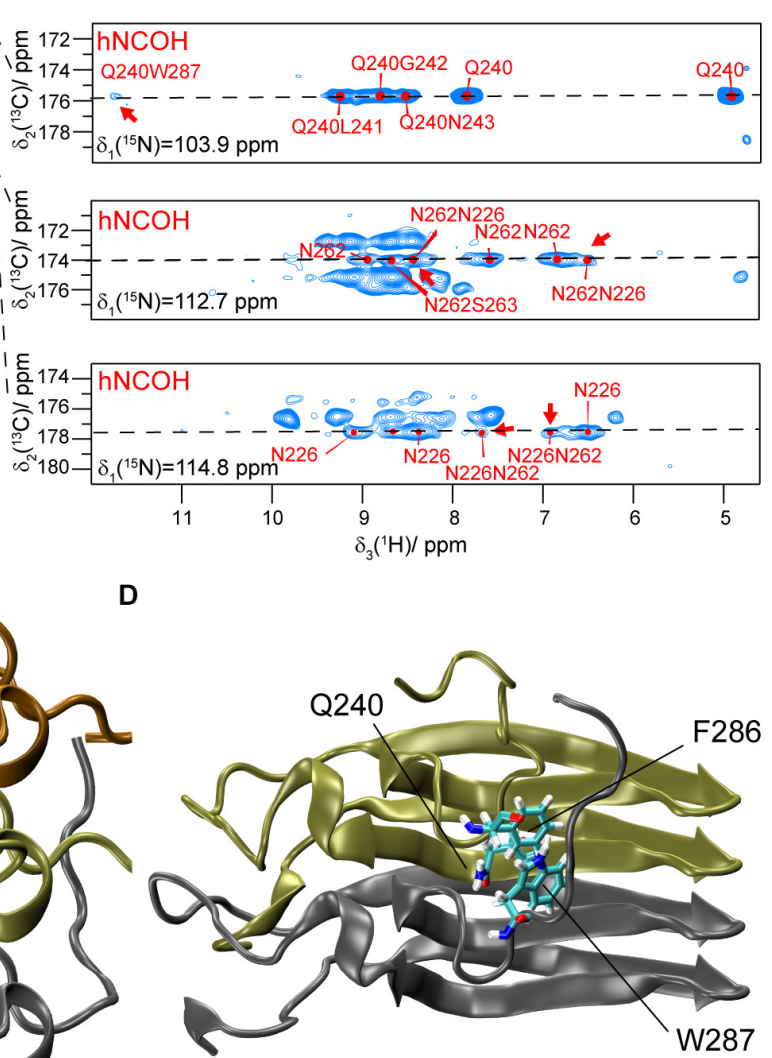

ring current effects
for Q240 sidechain

FIGURE 2 | Asparagine and glutamine side-chains in HET-s(218-289) fibrils. (A) ${ }^{1} \mathrm{H},{ }^{15} \mathrm{~N}$ CP-hNH spectrum of HET-s fibrils (left) and 2D planes of 3D hNCOH spectra showing spatial proximities for N226, N262 and Q240 (right, the cross peaks mentioned in the text are highlighted by red arrows). The spectra were recorded at a MAS frequency of $110 \mathrm{kHz}$ and an external magnetic field of $20.0 \mathrm{~T}$. The black dots indicate assigned backbone amide correlations based on the BMRB accession code 26913 (Smith et al., 2017). (B) Schematic drawing of an asparagine ladder. Circles indicate connectivities as expected for 3D hNCOH experiments.

(C) Asparagine ladders in HET-s highlighted on the PDB structure (PDB accession code 2KJ3). (D) Orientation of the Q240 side-chain toward aromatic residues in HET-s(218-289) highlighted on the PDB structure.

refocused INEPT-based hNH experiment (Sørensen and Ernst, 1983) could then be used to distinguish the $\mathrm{NH}_{2}$ proton resonances of N/Q side-chains from spectrally overlapping backbone $\mathrm{NH}$ resonances (for the chemical structures of N/Q side-chains see Figure 3A). By setting the INEPT delay $\tau_{\mathrm{N}}$ (Supplementary Figure S4) to $2.7 \mathrm{~ms}\left(\frac{1}{4 J_{\mathrm{NH}}}\right)$, the $\mathrm{NH}_{2}$ resonances will be strongly suppressed in the INEPT transfer; in contrast, when setting $\tau_{\mathrm{N}}$ close to $1.4 \mathrm{~ms}$, they appear in the spectra (see Figure 3B). For HET-s(218-289) only two of the seven $\mathrm{NH}_{2}$ pairs (assigned to Q240 and Q259) are visible in INEPT experiments (see Figure 3C). None out of the five asparagine residues is detected indicating that proton transverse magnetization lifetimes are too short to detect the HET-s(218289) asparagine side-chains in INEPT. We attribute this to dynamics as discussed below. Sample deuteration as used herein is crucial for INEPT experiments to prolong proton transverse magnetization lifetimes.

We envision that such INEPT-filtering experiments might also be helpful for large proteins to identify and further characterize the corresponding N/Q side-chain region in crowded NMR spectra. To test the feasibility of such an approach, we recorded INEPT-hNH spectra for the hexameric $354 \mathrm{kDa}$ protein DnaB (Wiegand et al., 2019; Wiegand, 2020) (complexed with $\mathrm{ADP}: \mathrm{AlF}_{\mathrm{x}}{ }^{-}$and DNA). Figure 3D shows a comparison of the spectra with $\tau_{\mathrm{N}}=1.2 \mathrm{~ms}$ (cyan) and $\tau_{\mathrm{N}}=2.7 \mathrm{~ms}$ (gray, for a difference spectrum see Supplementary Figure S5 and for further $\tau_{\mathrm{N}}$-times see Supplementary Figures S6, S7) and indeed several N/Q side-chains are identified at $110 \mathrm{kHz}$ MAS. We note that the INEPT spectra of this 488 residue protein (with $24 \mathrm{~N}$ and $23 \mathrm{Q}$ residues) are again rather sparse, also for the backbone amides, as the INEPT step filters out resonances with short transverse proton magnetization lifetimes that are on the other hand visible in $\mathrm{CP}-\mathrm{hNH}$ spectra (Wiegand et al., 2020).

\section{Asparagine Ladders}

In the amyloid fibrils of HET-s(218-289), two asparagine ladders (one comprising N226 and N262 and the other N243 and N279) 
A<smiles>CCC(C)C(N)=O</smiles><smiles>CCCCCCCC(N)=O</smiles>

$G \ln (Q)$

C
B

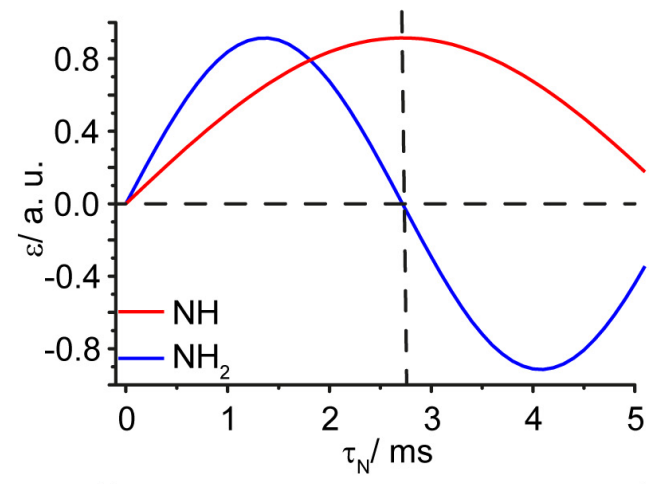

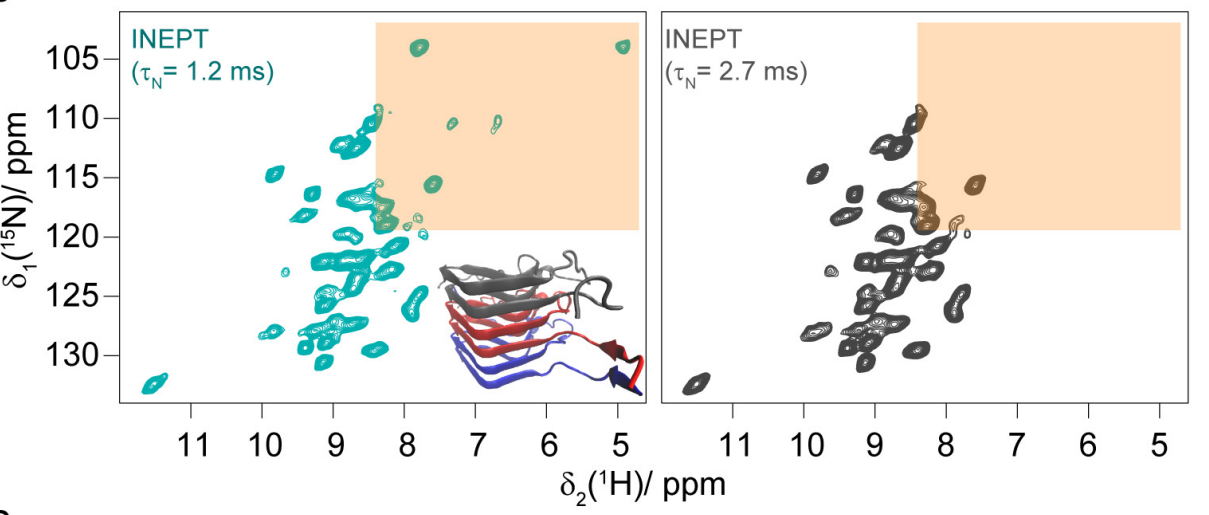

D

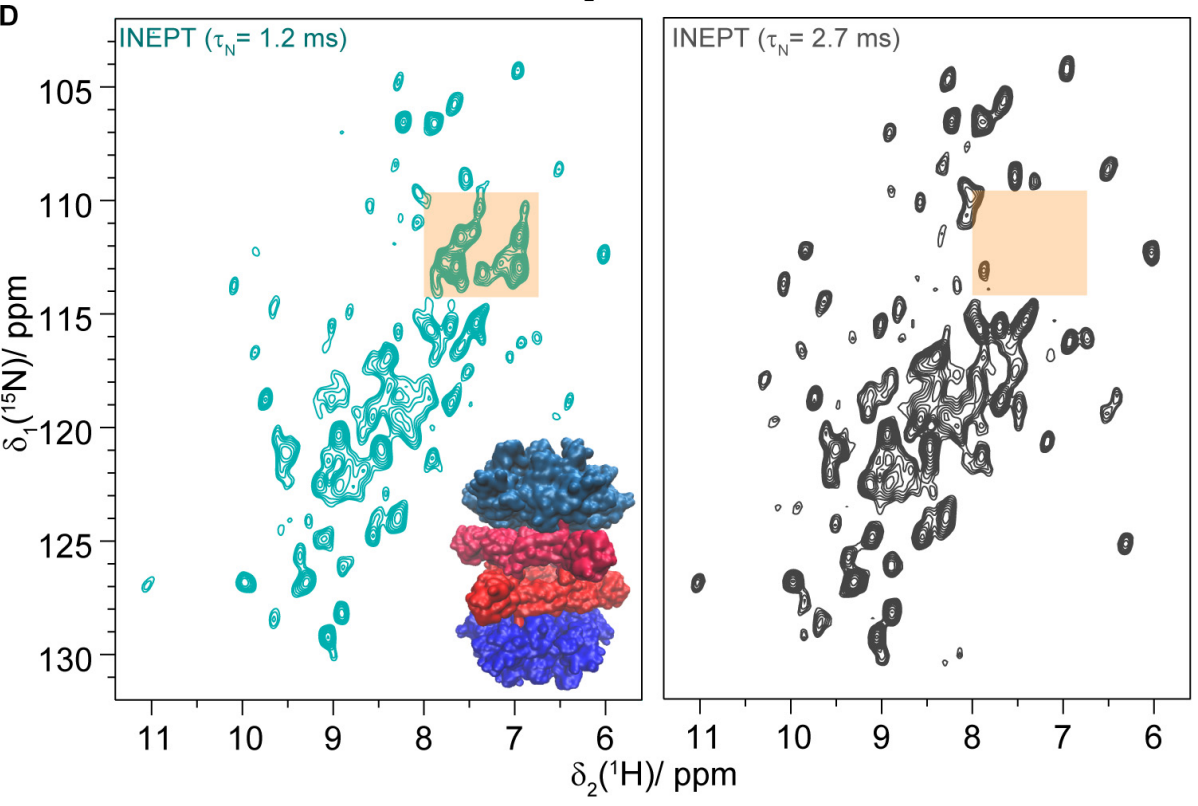

FIGURE 3 | Asparagine and glutamine side-chains identified in INEPT experiments. (A) Chemical structures of asparagine and glutamine side-chains.

(B) Dependence of the INEPT enhancement $\varepsilon$ on the $\tau_{\mathrm{N}}$ mixing time for $\mathrm{NH}$ (blue) and $\mathrm{NH}_{2}$ (red) spin pairs. $\tau_{\mathrm{H}}$ was set to $2 \mathrm{~ms}$, a ${ }^{15} \mathrm{~N}-{ }^{1} \mathrm{H} J$ coupling constant of $92 \mathrm{~Hz}$ was assumed and relaxation effects were neglected. (C) ${ }^{15} \mathrm{~N},{ }^{1} \mathrm{H}$ INEPT-hNH spectra of DUL HET-s(218-289) fibrils recorded with different $\tau_{\mathrm{N}}$ mixing times ( $\tau_{\mathrm{H}}$ was set to $2 \mathrm{~ms}$ ). The N/Q side-chain region is highlighted in orange. (D) ${ }^{15} \mathrm{~N},{ }^{1} \mathrm{H}$ INEPT-hNH spectra of DUL DnaB with different $\tau_{\mathrm{N}}$ mixing times. The $\mathrm{N} / \mathrm{Q}$ spectral region is highlighted in orange. The spectra were recorded at a MAS frequency of $110 \mathrm{kHz}$ and an external magnetic field of 20.0 T.

have been postulated from the structure obtained by solid-state NMR. N226 and N262 point to the inside of the fibril and are located next to the hydrophobic core, whereas N243 and N279 are outside of the core (see Figure 2C; Wasmer et al., 2008).
The NMR structure shows a well-formed ladder for N226/N262 in most structures of the structural bundle whereas N243/N279 do not form a regular ladder. It is, at this point not a priori clear if this difference is a consequence of the limited precision 
of the NMR structure or if it reflects real structural differences. Such small, but potentially important structural features are not easily addressed by cryo-EM or NMR structures. However, spectroscopic features may be exploited: the proton chemical shift itself is highly sensitive to changes in the environment and can be used as an indicator for hydrogen bonding (Cordier and Grzesiek, 1999) characteristic for ladders (see Figure 2). As illustrated in Density Functional Theory (DFT) calculations on a model consisting of two asparagine side-chains engaged in a hydrogen bond, see Figure 4 and Supplementary Figure S8, a significant de-shielding of the $\mathrm{H}_{Z}$ proton (see insert of Figure 4 for the nomenclature) participating in a hydrogen bond is observed. In one calculation, two asparagine side-chain fragments were moved relative to each other along the $\mathrm{N}-\mathrm{H}^{\cdots} \mathrm{O}$ distance vector (Figure 4), while in the second calculation only the $\mathrm{H}_{\mathrm{Z}}$ proton was moved along that vector and all other atoms of the two fragments were kept fixed (Supplementary Figure S8). Both cases reveal that the shorter the hydrogen bond, the larger the chemical-shift difference between the $\mathrm{H}_{Z}$ and $\mathrm{H}_{\mathrm{E}}$ protons (Barfield, 2002). We speculate that the scenario described in Figure 4 is more likely reflecting the situation in asparagine ladders, although not only the hydrogen bond length effects the strength of the hydrogen bond and thus the proton chemical-shift values observed experimentally, but also the bond angle certainly has an influence.

Experimentally, for N226 we find a large difference between the two proton resonances resonating at 8.4 and $6.5 \mathrm{ppm}$. For $\mathrm{N} 262$ the less-shielded value is $7.6 \mathrm{ppm}$ compared to $6.8 \mathrm{ppm}$ for the more-shielded one. The two $\mathrm{NH}_{2}$ protons are thus shifted in different directions with respect to their average chemical-shift values over all deposited asparagine residues as extracted from the BMRB database (7.3 and $7.1 \mathrm{ppm})^{1}$.

${ }^{1}$ http://www.bmrb.wisc.edu

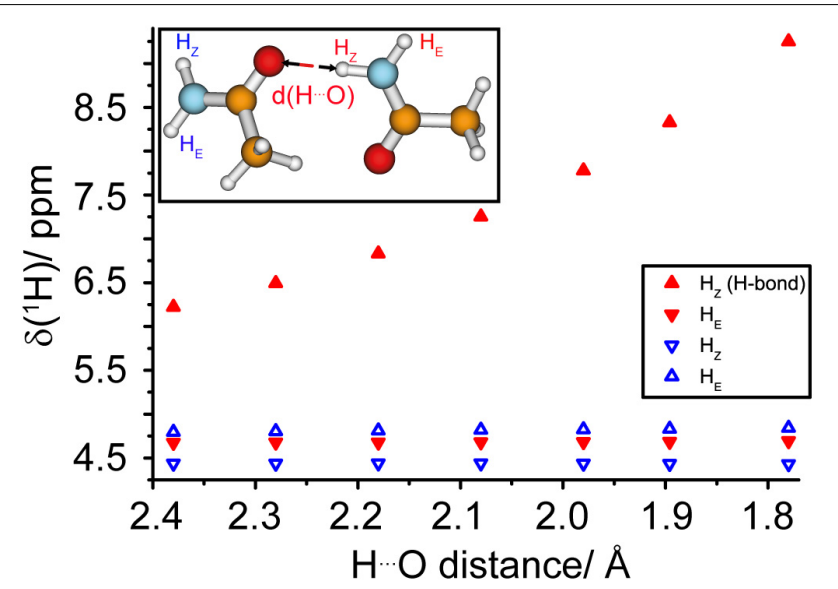

FIGURE 4 | The proton chemical shift is a sensitive tool to measure hydrogen bond strengths in asparagine ladders. DFT calculations (B3-LYP/def2-TZVP) of ${ }^{1} \mathrm{H}$ chemical-shift values as a function of the hydrogen bond length in a model representing two asparagine side-chains. The geometries of the two molecules were fixed and the two fragments were moved relative to each other along the $\mathrm{N}-\mathrm{H} \cdots \mathrm{O}$ distance vector, see insert.
3D hNCOH experiments (Figure 2B) do not only identify the two protons in the same $\mathrm{NH}_{2}$ group, but also probe the spatial proximity between such side-chains. A $9 \mathrm{~ms}{ }^{13} \mathrm{CO}$ ${ }^{1} \mathrm{H}$ CP-step was employed to achieve a polarization transfer to both $\mathrm{NH}_{2}$ protons of the neighboring asparagine sidechain within the same ladder. Similar experiments have been described recently to identify backbone hydrogen bonding patterns in SH3 and GB1 (Friedrich et al., 2020). And indeed, the ${ }^{15} \mathrm{~N}$ planes at the $\mathrm{NH}_{2}$ side-chain chemical-shift value of N262 (112.7 ppm) and N226 (114.8 ppm) clearly show cross peaks to the proton shifts of the $\mathrm{NH}_{2}$ group of N226 and N262, respectively (see Figure 2A, red arrows) indicating their spatial proximity. In HET-s(218-289) this information corroborates the known register in the $\beta$-sheets and in other systems of unknown structure this may be of even more interest. For residues N243/N279 that form the second asparagine ladder no signals are detected in the CP-based 3D hNCOH spectrum.

\section{Homogeneous Proton Linewidths of Asparagine and Glutamine Side-Chains}

The visibility of the proton resonances in INEPT-type experiments is related to the homogeneous proton linewidth ( $\Delta^{\text {homo }}$ ) which is determined by the geometry of the proton dipolar network (coherent contribution; Zorin et al., 2006; Sternberg et al., 2018; Malär et al., 2019), additional additive contributions resulting from Redfield-type relaxation caused by stochastic molecular motion (incoherent contribution from anisotropic interactions) and chemical-exchange broadening effects (incoherent contributions from isotropic chemical-shift differences) (Sternberg et al., 2018; Malär et al., 2019; Penzel et al., 2019). Unfortunately, the three contributions cannot easily be addressed separately, and only their sum is observed experimentally. Coherent and incoherent contributions are expected to decrease with faster spinning (Lewandowski et al., 2011; Andreas et al., 2015; Böckmann et al., 2015; Sternberg et al., 2018; Malär et al., 2019; Penzel et al., 2019) while chemical exchange is largely MAS-frequency independent. Spin-echo decay experiments allow determination of proton $T_{2}{ }^{\prime}$ relaxation times and $\Delta^{\text {homo }}=R_{2}{ }^{\prime} / \pi=1 /\left(\pi T_{2}{ }^{\prime}\right)$ values. The pulse sequences used to measure $\Delta^{\text {homo }}$ values are shown in Supplementary Figure S9.

For HET-s(218-289) fibrils, $\Delta^{\text {homo }}$ values between 80 and $160 \mathrm{~Hz}$ for the N226, N243 and N262 side-chain protons are observed (see Figures 5A,B) which explains why these resonances remain absent in INEPT experiments (a $\Delta^{\text {homo }}$ of $160 \mathrm{~Hz}, T_{2}^{\prime} \sim 2 \mathrm{~ms}$, would lead to an attenuation of $\sim 88 \%$ in the refocused INEPT efficiency with INEPT delays of $\tau_{\mathrm{H}}=2.0 \mathrm{~ms}$ and $\tau_{\mathrm{N}}=1.2 \mathrm{~ms}$ ). $\Delta^{\text {homo }}$ for N279 is even larger $(543 \pm 140 \mathrm{~Hz})$. All these values are significantly larger than the corresponding values of the backbone amide protons, which have been reported before, showing on average $22 \pm 1 \mathrm{~Hz}$ at $100 \mathrm{kHz}$ MAS for DUL HET-s(218-289) (Smith-Penzel, 2019). The glutamine side-chains which are easily observed in INEPT-hNH have, as expected, a smaller $\Delta^{\text {homo }}$ value $(<50 \mathrm{~Hz})$. As an additional reference we also measured the 

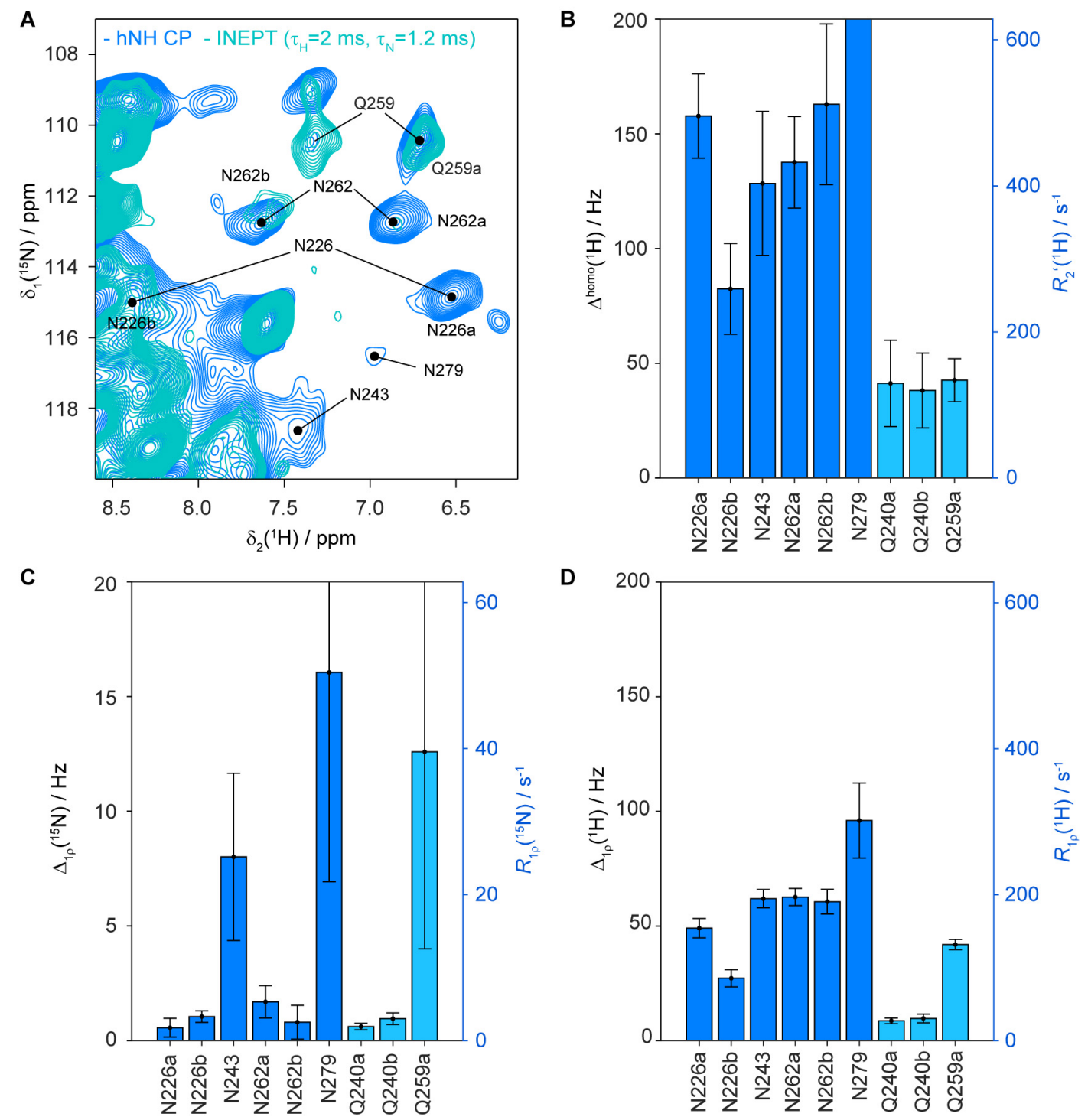

FIGURE 5 | Homogeneous proton linewidths and ${ }^{15} \mathrm{~N}$ and ${ }^{1} \mathrm{H} \mathrm{R}_{1}$ rate constants of asparagine and glutamine side-chains in HET-s(218-289) fibrils. Zoom into INEPT-hNH (cyan) and CP-hNH (blue) spectra of HET-s(218-289) fibrils (A) showing the asparagine and glutamine side-chain region and some resonance assignments. Homogeneous proton linewidths for asparagine and glutamine side-chains of HET-s(218-289) fibrils are given in (B). Nitrogen spin-lock relaxation rate constants of asparagine and glutamine side-chains are shown in (C), proton spin-lock relaxation times in (D). All error bars shown correspond to two standard deviations. The relaxation rate constants given on the vertical axis are related according to $\Delta=R / \pi$. The relaxation times were determined at a MAS frequency of $105 \mathrm{kHz}$ and an external magnetic field of $20.0 \mathrm{~T}$.

homogeneous proton linewidths for asparagine and glutamine side-chains in DnaB. In accordance with the experimental observation of glutamine side-chains in INEPT spectra, the $\Delta^{\text {homo }}$ are indeed smaller and amount on average to $31 \pm 5 \mathrm{~Hz}$ (Supplementary Figure S10).

To investigate whether the larger-than-expected $\Delta^{\text {homo }}$ values observed for the asparagine side-chains are related to coherent broadening mechanisms, we have numerically simulated the ${ }^{1} \mathrm{H}$ solid-state NMR spectrum using the geometry of the six $\mathrm{NH}_{2}$ proton spins of N262-N226-N262 taken from the PDB file (Figure 1, PDB accession number $2 \mathrm{KJ} 3$, the chosen geometry is taken from structure 16 in which the asparagine ladder N226/N262 is most clearly visible, see also Supplementary Figure S11A). Those simulations yield $\Delta^{\text {homo }}$ values of less than $5 \mathrm{~Hz}$ (see Supplementary Figure S11B) which illustrates that the main contribution to $\Delta^{\text {homo }}$ is not related to coherent effects resulting from the geometry within an asparagine ladder even if the contribution from a close-by backbone amide is taken into account (Supplementary Figure S12). The numerically simulated spin-echo decay profile using the same six-spin system are shown in Supplementary Figure S11C and also give a negligible $\Delta^{\text {homo }}$ value of $2 \mathrm{~Hz}$. Cross terms between 
heteronuclear ${ }^{15} \mathrm{~N}-{ }^{1} \mathrm{H}$ dipolar and/or $J$-couplings and the proton homonuclear dipolar couplings were also not found to make an appreciable contribution (Supplementary Figure S11C).

\section{${ }^{15} \mathrm{~N}$ Rotating-Frame Relaxation Rates of Asparagine and Glutamine Side-Chains: Rigid Side-Chains in Asparagine Ladders}

${ }^{15} \mathrm{~N}$ rotating-frame relaxation rate constants, characterized by $R_{1 \rho}$, may give further information about the dynamics of asparagine and glutamine side-chains (for the pulse sequences see Supplementary Figure S13 and for the site-specific decay curves Supplementary Figures S14, S15). Under the experimental conditions used $(110 \mathrm{kHz}$ MAS, $13 \mathrm{kHz}$ rf-field amplitude for the spin lock) the experiment is sensitive to dynamics with correlation times in the hundreds of nanoseconds to low microsecond range (Lakomek et al., 2017). Figure 5C shows the ${ }^{15} \mathrm{~N} R_{1 \rho}$ experimental relaxation-rate constants for HET-s(218-289) fibrils. Typical rigid backbone nitrogen atoms possess $R_{1 \rho}$ values of around $2 \mathrm{~s}^{-1}$ (Schanda and Ernst, 2016; Lakomek et al., 2017). The values for the side-chain $\mathrm{NH}_{2}$ nitrogen of $\mathrm{N} 226$ and N262 are also in the order of $2 \mathrm{~s}^{-1}$ indicating the absence of dynamics on this timescale for side-chain nitrogen (for details on relaxation properties of $\mathrm{NH}_{2}$ spin systems see Bull (1992). Interestingly, N243 and $\mathrm{N} 279$ show significantly larger ${ }^{15} \mathrm{~N} R_{1 \rho}\left(>25 \mathrm{~s}^{-1}\right)$ pointing to a higher degree of flexibility of these side-chains. Based on the measured $R_{1 \rho}$ values, the side-chain of Q240 is similarly rigid as N226 and N262, whereas Q259 is more flexible and shows weaker correlations in ${ }^{13} \mathrm{C}$-detected $3 \mathrm{D}$ spectra (see Supplementary Figure S2). In DnaB, which does not contain N/Q ladders, the side-chain nitrogen $R_{1 \rho}$ relaxation-rate constants are ranging between 10 and $32 \mathrm{~s}^{-1}$ (see Supplementary Figure S10C) and are, thus, larger than for the rather rigid N226/N262 side-chains of HET-s(218289) fibrils.

The higher rigidity of the ladder N226/N262 compared to N243/N279 might be a consequence of a higher water accessibility of N243/N279 in agreement with their location outside of the hydrophobic core. All asparagine residues influence the fibril stability in the presence of guanidine as a chemical denaturant as shown by site-directed mutagenisis (Wan and Stubbs, 2014). However, mutation of N226 and N262 yields more destabilization than mutation of N243 and especially $\mathrm{N} 279$, in the latter mutant a similar chemical stability than in wild-type HET-s(218-289) fibrils was observed (Wan and Stubbs, 2014).

Since so far coherent and incoherent broadening mechanisms cannot account for the observed proton homogeneous linewidth, we also consider the possibility of chemicalexchange broadening, namely slow to intermediate exchange (below coalescence) on a millisecond timescale to explain the broader-than-expected lines. Such processes have been observed for asparagine side-chains in T4 lysozyme (Mulder et al., 2001) or in coiled-coil homo dimers (Thomas et al., 2017) in solution. The exchange is most likely asymmetric with one dominating conformer which is detected in our spectra. In our model, the conformational states represent asparagine side-chains hydrogen-bonded in a ladder (the most populated state observed experimentally) and an additional so far unobserved state. We performed ${ }^{15} \mathrm{~N}$ chemical-exchange saturation transfer (CEST) experiments (Vallurupalli et al., 2012), but were not able to observe this state requiring further experimental work. The $\mathrm{NH}_{2}$ proton relaxation-rate constants in the rotating frame measured for the asparagine side-chains are larger compared to backbone amides possibly as a consequence of a modulation of the proton homonuclear dipolar couplings by the exchange process (see Figure 5D and Supplementary Figure S16). However, the exchange contribution to the measured proton $R_{1 \rho}$ values is negligible at a spin-lock field of $13 \mathrm{kHz}$ as used in our experiment (Palmer and Massi, 2006). Whether this observation is a general feature of N/Q ladders has to be investigated on further amyloid fibrils in future work, it is however interesting that the glutamine sidechains in HET-s(218-289) do not show these effects, and their homogeneous linewidths are roughly by a factor of three smaller.

TABLE 1 | Overview of asparagine and glutamine side-chain spectral and relaxation properties.

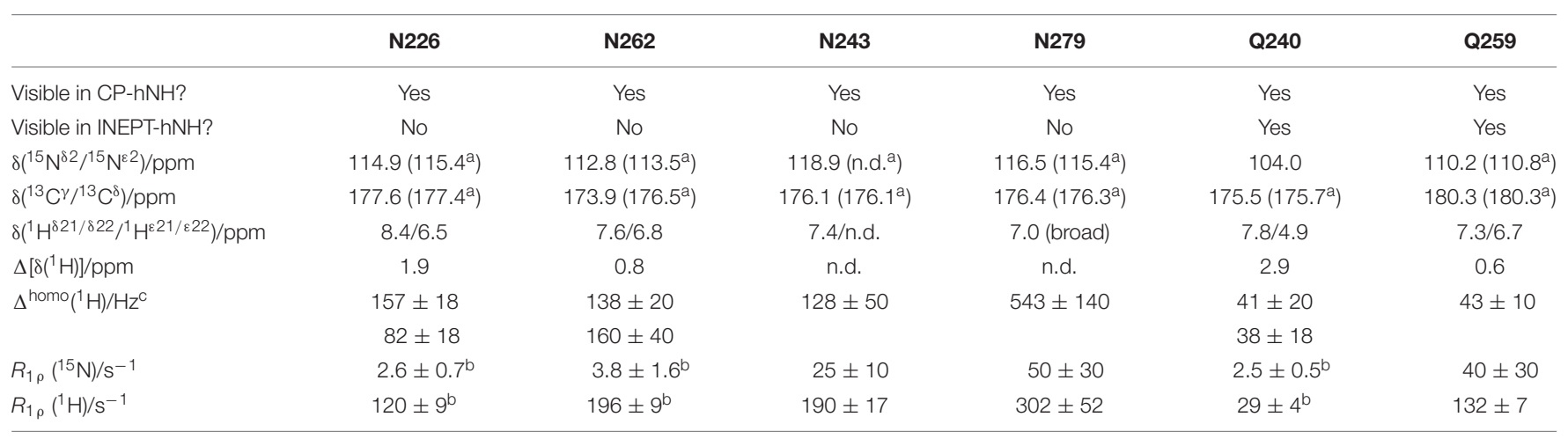

${ }^{a}$ Determined on protonated HET-s fibrils in ${ }^{13} \mathrm{C}$-detected MAS experiments (BMRB accession code 11064). Differences to the values derived from ${ }^{1} \mathrm{H}$-detected experiments are related to temperature differences in the experiments. ${ }^{b}$ The average value over the relaxation rate constants for both resonances is given. The error is derived by error propagation of the individual experimental errors (a $2 \sigma$ error is given). ${ }^{c} \Delta^{\text {homo }}$ is calculated according to $R_{2}{ }^{\prime} / \pi=1 /\left(\pi T_{2}{ }^{\prime}\right)$. 


\section{Characterization of Glutamine Side-Chains and the Orientation of Q240}

For the two glutamine side-chains of HET-s(218-289), no ladder formation is possible from the structure (Van Melckebeke et al., 2010). Both glutamine side-chain $\mathrm{NH}_{2}$ are observed in the $\mathrm{CP}$ and INEPT-spectra (Figures 2A, 3D). For Q240, one proton is shifted to the more shielded region (4.8 ppm), the other one is at $7.8 \mathrm{ppm}$, slightly less shielded compared to the average chemical shift values taken from the BMRB database (7.22/7.04 ppm). The increased shielding of one of the $\mathrm{NH}_{2}$ proton of Q240 might be associated with ring-current effects, since Q240 points toward a hydrophobic pocket constituted by aromatic residues (F286 and W287, Figure 2D; Van Melckebeke et al., 2010). The cross signal between Q240 and W287 in the 3D hNCOH experiment reveals that the side-chain of Q240 is indeed in spatial proximity to the side-chain NH group of W287 (Figure 2A).

\section{CONCLUSION}

We detected asparagine and glutamine $\mathrm{NH}_{2}$ side-chains proton signals in fast MAS spectra of HET-s(218-289) in its amyloid form. The spectral and relaxation properties are described and the influence of the formation of ladders is investigated. Table 1 summarizes the NMR properties of such side-chains. The following observations were made for the asparagines involved in a well-formed ladder: (i) strong de-shielding of the proton shift of one of the $\mathrm{NH}_{2}$ protons, (ii) a large chemical-shift difference between the two protons, (iii) correlations in 3D throughspace hCONH experiments, and (iv) small ${ }^{15} \mathrm{~N} R_{1 \rho}$ relaxationrate constants. These properties characterize the N226-N262 asparagine ladder. In addition (v) a large homogeneous proton linewidth and (vi) a large ${ }^{1} \mathrm{H} R_{1 \rho}$ relaxation-rate constants were found. ${ }^{15} \mathrm{~N}$ rotating-frame relaxation rate constants indicate that the side-chains involved into the N226-N262 asparagine ladder are more rigid than for the N243-N279 ladder which appear more dynamic not forming a strong restraining hydrogen network. The large homogeneous proton linewidths for asparagine sidechains involved in the ladder, not fully understood yet, could be related to millisecond timescale chemical exchange characteristic for protons engaged in an asparagine ladder in HET-s(218289) fibrils. The glutamine side-chain amide protons of HET$s(218-289)$ not participating in such interactions are less homogeneously broadened and have linewidths comparable to the backbone NH protons. Fast MAS NMR experiments thus probe protein side-chain hydrogen bonding, in particular in the context of asparagine/glutamine ladder formation. While more systems must be investigated for a full understanding, the results on HET-s(218-289) clearly show the potential of the approach.

\section{MATERIALS AND METHODS}

\section{Protein Preparations}

The preparations of the DUL $H p D n a B: A D P: \mathrm{AlF}_{4}{ }^{-}$:DNA (Wiegand et al., 2019) and DUL HET-s(218-289) (Wasmer et al., 2008) samples were prepared as described previously. In short, the proteins were recombinantly expressed in $\mathrm{D}_{2} \mathrm{O}$ in presence of deuterated ${ }^{13} \mathrm{C}$-glucose $(2 \mathrm{~g} / \mathrm{L})$ and ${ }^{15} \mathrm{~N}$-ammonium chloride $(2 \mathrm{~g} / \mathrm{L})$ as sole sources of carbon-13 and nitrogen-15. In case of HET-s(218-289), fibrillization was performed in protonated solvent $\left(50 \mathrm{mM}\right.$ citric acid at $\mathrm{pH} 5$ in $\left.\mathrm{H}_{2} \mathrm{O}\right)$ for $24 \mathrm{~h}$ which yields $100 \%$ back-exchanged fibrils (Smith et al., 2017). For DnaB, back-exchange was achieved by purifying the protein in a protonated buffer $(2.5 \mathrm{mM}$ sodium phosphate, $\mathrm{pH} 7.5$, $130 \mathrm{mM} \mathrm{NaCl})$. The complex formation with $\mathrm{ADP}: \mathrm{AlF}_{\mathrm{x}}{ }^{-}$and DNA (a single-stranded DNA molecule with 20 thymine bases was used, purchased from Microsynth) is described in reference Wiegand et al. (2019). UL HET-s(218-289) fibrils were prepared identically, but only using $\mathrm{H}_{2} \mathrm{O}$ instead of $\mathrm{D}_{2} \mathrm{O}$ and protonated ${ }^{13} \mathrm{C}$-glucose $(2 \mathrm{~g} / \mathrm{L})$ and ${ }^{15} \mathrm{~N}$-ammonium chloride $(2 \mathrm{~g} / \mathrm{L})$.

\section{Solid-State NMR}

Solid-state NMR spectra were acquired at $20.0 \mathrm{~T}$ static magnetic-field strength using a Bruker $0.7 \mathrm{~mm}$ probe. The MAS frequency was set to $110 \mathrm{kHz}$. The $2 \mathrm{D}$ spectra were processed with the software TOPSPIN (version 3.5, Bruker Biospin) with a shifted (3.0) squared cosine apodization function and automated baseline correction in the indirect and direct dimensions. The sample temperature was set to $293 \mathrm{~K}$ (Böckmann et al., 2009). All spectra were analyzed with the software CcpNmr (Fogh et al., 2002; Vranken et al., 2005; Stevens et al., 2011) and referenced to 4,4-dimethyl4-silapentane-1-sulfonic acid (DSS). Site-specific relaxationrate constants were extracted from the $2 \mathrm{D} \mathrm{hNH}$ relaxation experiments, using the INFOS software (Smith, 2017) (see Supplementary Figures S14, S15 for the mono-exponential fits of all relaxation decay curves for DUL HET-s). Error bars for all relaxation data have been derived by bootstrapping methods, using 500 iterations and are shown as $2 \sigma$, where $\sigma$ denotes the obtained error. For more details see Supplementary Table S1. The NMR spectra can be accessed at https://doi.org/10.3929/ ethz-b-000430151.

\section{Numerical Simulations}

The numerical simulations of ${ }^{1} \mathrm{H}$ MAS spectra were performed with SIMPSON (Bak et al., 2000) using six proton spins in the geometry extracted from the pdb file 2JK3 (structure 16). The spin-echo decay curves were obtained using the same proton six-spin system with and without three nitrogen spins. The simulations were performed in the GAMMA spin simulations environment (Smith et al., 1994). The program code for the simulations is provided in the Supplementary Material.

\section{DFT Calculations}

The DFT calculations were performed with TURBOMOLE (Ahlrichs et al., 1989) version 6.4.0. Geometry optimizations were performed on a B3-LYP (Stephens et al., 1994)/def2-TZVP (Weigend and Ahlrichs, 2005) level employing the D3 dispersion correction (Grimme et al., 2010). In all TURBOMOLE SCF calculations, an energy convergence criterion of $10^{-7} \mathrm{E}_{\mathrm{h}}$ was used, and in the geometry optimizations, an energy convergence criterion of $10^{-6} \mathrm{E}_{\mathrm{h}}$ was employed. The integration grid was set to m4. Magnetic shieldings were calculated within the GIAO 
framework on the same theoretical level and converted into chemical-shift values according to $\delta=\sigma_{\text {ref }}-\sigma$ with $\sigma_{\text {ref }}$ being the magnetic shielding of the protons of TMS calculated at the same level of theory $\left(\sigma_{\text {ref }}=31.9 \mathrm{ppm}\right)$. The orientationdependence of the ${ }^{1} \mathrm{H}$ chemical-shift values was studied by moving the two molecules relative to each other along the $\mathrm{N}-\mathrm{H} \cdots$ $\mathrm{O}$ distance vector (Figure 4) or moving the proton only along that vector (Supplementary Figure S8). No additional geometry optimization was performed.

\section{DATA AVAILABILITY STATEMENT}

All datasets generated for this study are included in the article/Supplementary Material.

\section{AUTHOR CONTRIBUTIONS}

RC prepared the samples. TW and AM performed the NMR experiments. TW, $\mathrm{AM}, \mathrm{ME}, \mathrm{AB}$, and $\mathrm{BM}$ analyzed the data. TW and ME performed the simulations. TW, AB, ME, and BM designed and supervised the research. All authors contributed to the writing of the manuscript.

\section{REFERENCES}

Agarwal, V., Penzel, S., Szekely, K., Cadalbert, R., Testori, E., Oss, A., et al. (2014). De Novo 3D structure determination from sub-milligram protein samples by solid-State $100 \mathrm{kHz}$ MAS NMR spectroscopy. Angew. Chem. Int. Ed. 53, 12253-12256. doi: 10.1002/anie.201405730

Ahlrichs, R., Bär, M., Häser, M., Horn, H., and Kölmel, C. (1989). Electronic structure calculations on workstation computers: the program system turbomole. Chem. Phys. Lett. 162, 165-169. doi: 10.1016/0009-2614(89)85 $118-8$

Andreas, L. B., Jaudzems, K., Stanek, J., Lalli, D., Bertarello, A., Le Marchand, T., et al. (2016). Structure of fully protonated proteins by proton-detected magic-angle spinning NMR. Proc. Natl. Acad. Sci. U.S.A. 113, 9187-9192.

Andreas, L. B., Le Marchand, T., Jaudzems, K., and Pintacuda, G. (2015). Highresolution proton-detected NMR of proteins at very fast MAS. J. Magn. Reson. 253, 36-49. doi: 10.1016/j.jmr.2015.01.003

Bak, M., Rasmussen, J. T., and Nielsen, N. C. (2000). SIMPSON: a general simulation program for solid-state NMR spectroscopy. J. Magn. Reson. 147, 296-330. doi: 10.1006/jmre.2000.2179

Barfield, M. (2002). Structural dependencies of interresidue scalar coupling h3JNC and donor $1 \mathrm{H}$ chemical shifts in the hydrogen bonding regions of proteins. J. Am. Chem. Soc. 124, 4158-4168. doi: 10.1021/ja012674v

Böckmann, A., Ernst, M., and Meier, B. H. (2015). Spinning proteins, the faster, the better? J. Magn. Reson. 253, 71-79. doi: 10.1016/j.jmr.2015.01.012

Böckmann, A., Gardiennet, C., Verel, R., Hunkeler, A., Loquet, A., Pintacuda, G., et al. (2009). Characterization of different water pools in solid-state NMR protein samples. J. Biomol. NMR 45, 319-327. doi: 10.1007/s10858-009-9374-3

Buck, M., Boyd, J., Redfield, C., MacKenzie, D. A., Jeenes, D. J., Archer, D. B., et al. (1995). Structural determinants of protein dynamics: analysis of 15N NMR relaxation measurements for main-chain and side-chain nuclei of hen egg white lysozyme. Biochemistry 34, 4041-4055. doi: 10.1021/bi00012a023

Bull, T. E. (1992). Relaxation in the rotating frame in liquids. Prog. Nucl. Magn. Reson. Spectrosc. 24, 377-410. doi: 10.1016/0079-6565(92)80002-w

Cai, M., Huang, Y., and Clore, G. M. (2001). Accurate orientation of the functional groups of asparagine and glutamine side chains using one- and two-bond dipolar couplings. J. Am. Chem. Soc. 123, 8642-8643. doi: 10.1021/ja0164475

\section{FUNDING}

This work was supported by the ETH Career SEED-69 16-1 (TW) and the ETH Research Grant ETH-43 17-2 (TW), an ERC Advanced Grant (BM, Grant No. 741863, Faster), by the Swiss National Science Foundation (BM, Grant Nos. 200020_159707 and 200020-188711, ME, Grant No. 200020_188988), the French Agence Nationale de Recherche (AB, ANR-14-CE09-0024B), and the LABEX ECOFECT (AB, ANR-11-LABX-0048) within the Université de Lyon program Investissements d'Avenir (AB, ANR11-IDEX-0007).

\section{ACKNOWLEDGMENTS}

TW thanks Denis Lacabanne for helpful discussions.

\section{SUPPLEMENTARY MATERIAL}

The Supplementary Material for this article can be found online at: https://www.frontiersin.org/articles/10.3389/fmolb. 2020.582033/full\#supplementary-material

Colvin, M. T., Silvers, R., Ni, Q. Z., Can, T. V., Sergeyev, I., Rosay, M., et al. (2016). Atomic resolution structure of monomorphic A $\beta 42$ amyloid fibrils. J. Am. Chem. Soc. 138, 9663-9674. doi: 10.1021/jacs.6b05129

Cordier, F., and Grzesiek, S. (1999). Direct observation of hydrogen bonds in proteins by interresidue 3hJNC' scalar couplings. J. Am. Chem. Soc. 121, 1601-1602. doi: 10.1021/ja983945d

Eisenberg, D. S., and Sawaya, M. R. (2017). Structural studies of amyloid proteins at the molecular level. Annu. Rev. Biochem 86, 69-95. doi: 10.1146/annurevbiochem-061516-045104

Fogh, R., Ionides, J., Ulrich, E., Boucher, W., Vranken, W., Linge, J. P., et al. (2002). The CCPN project: an interim report on a data model for the NMR community. Nat. Struct. Mol. Biol. 9, 416-418. doi: 10.1038/nsb0602-416

Friedrich, D., Perodeau, J., Nieuwkoop, A. J., and Oschkinat, H. (2020). MAS NMR detection of hydrogen bonds for protein secondary structure characterization. J. Biomol. NMR 74, 247-256. doi: 10.1007/s10858-020-00307-z

Gremer, L., Schölzel, D., Schenk, C., Reinartz, E., Labahn, J., Ravelli, R. B. G., et al. (2017). Fibril structure of amyloid- $\beta(1-42)$ by cryo-electron microscopy. Science 358, 116-119. doi: 10.1126/science.aao2825

Grimme, S., Antony, J., Ehrlich, S., and Krieg, H. (2010). A consistent and accurate ab initio parametrization of density functional dispersion correction (DFTD) for the 94 elements H-Pu. J. Chem. Phys. 132:154104. doi: 10.1063/1.338 2344

Guenneugues, M., Drevet, P., Pinkasfeld, S., Gilquin, B., Ménez, A., and ZinnJustin, S. (1997). Picosecond to hour time scale dynamics of a "three finger" toxin: correlation with its toxic and antigenic properties. Biochemistry 36, 16097-16108. doi: 10.1021/bi971293k

Guerrero-Ferreira, R., Taylor, N. M. I., Arteni, A.-A., Kumari, P., Mona, D., Ringler, P., et al. (2019). Two new polymorphic structures of human full-length alpha-synuclein fibrils solved by cryo-electron microscopy. eLife 8:e48907.

Guerrero-Ferreira, R., Taylor, N. M. I., Mona, D., Ringler, P., Lauer, M. E., Riek, R., et al. (2018). Cryo-EM structure of alpha-synuclein fibrils. eLife 7:e36402.

Hervas, R., Rau, M. J., Park, Y., Zhang, W., Murzin, A. G., Fitzpatrick, J. A. J., et al. (2020). Cryo-EM structure of a neuronal functional amyloid implicated in memory persistence in Drosophila. Science 367, 1230-1234. doi: 10.1126/ science.aba3526 
Higman, V. A., Boyd, J., Smith, L. J., and Redfield, C. (2004). Asparagine and glutamine side-chain conformation in solution and crystal: a comparison for hen egg-white lysozyme using residual dipolar ouplings. J. Biomol. NMR 30, 327-346. doi: 10.1007/s10858-004-3218-y

Hoop, C. L., Lin, H. K., Kar, K., Magyarfalvi, G., Lamley, J. M., Boatz, J. C., et al. (2016). Huntingtin exon 1 fibrils feature an interdigitated beta-hairpinbased polyglutamine core. Proc. Natl. Acad. Sci. U.S.A. 113, 1546-1551. doi: 10.1073/pnas.1521933113

Klein, S. A., Majumdar, A., and Barrick, D. (2019). A second backbone: the contribution of a buried asparagine ladder to the global and local stability of a leucine-rich repeat protein. Biochemistry 58, 3480-3493. doi: 10.1021/acs. biochem. $9 \mathrm{~b} 00355$

Kollmer, M., Close, W., Funk, L., Rasmussen, J., Bsoul, A., Schierhorn, A., et al. (2019). Cryo-EM structure and polymorphism of $A \beta$ amyloid fibrils purified from Alzheimer's brain tissue. Nat. Commun. 10:4760.

Kurt, T. D., Aguilar-Calvo, P., Jiang, L., Rodriguez, J. A., Alderson, N., Eisenberg, D. S., et al. (2017). Asparagine and glutamine ladders promote cross-species prion conversion. J. Biol. Chem. 292, 19076-19086. doi: 10.1074/jbc.m117. 794107

Lakomek, N.-A., Penzel, S., Lends, A., Cadalbert, R., Ernst, M., and Meier, B. H. (2017). Microsecond dynamics in ubiquitin probed by solid-state $15 \mathrm{~N}$ NMR spectroscopy R1 $\rho$ relaxation experiments under fast MAS $(60-110 \mathrm{kHz})$. Chem. Eur. J. 23, 9425-9433. doi: 10.1002/chem.201701738

Lejeune, D., Delsaux, N., Charloteaux, B., Thomas, A., and Brasseur, R. (2005). Protein-nucleic acid recognition: statistical analysis of atomic interactions and influence of DNA structure. Proteins Struct. Funct. Bioinform. 61, 258-271. doi: $10.1002 /$ prot. 20607

Lewandowski, J. R., Dumez, J.-N., Akbey, Ü, Lange, S., Emsley, L., and Oschkinat, H. (2011). Enhanced resolution and coherence lifetimes in the solid-state NMR spectroscopy of perdeuterated proteins under ultrafast magic-angle spinning. J. Phys. Chem. Lett. 2, 2205-2211. doi: 10.1021/jz200844n

Luckgei, N., Schütz, A. K., Bousset, L., Habenstein, B., Sourigues, Y., Gardiennet, C., et al. (2013). The conformation of the prion domain of Sup35p in isolation and in the full-length protein. Angew. Chem. Int. Ed. 52, 12741-12744. doi: 10.1002/anie.201304699

Luscombe, N. M., Laskowski, R. A., and Thornton, J. M. (2001). Amino acid-base interactions: a three-dimensional analysis of protein-DNA interactions at an atomic level. Nucleic Acids Res. 29, 2860-2874. doi: 10.1093/nar/29.13.2860

Malär, A. A., Dong, S., Kehr, G., Erker, G., Meier, B. H., and Wiegand, T. (2019). Characterization of $\mathrm{H} 2$-splitting products of frustrated lewis pairs: benefit of fast magic-angle spinning. ChemPhysChem 20, 672-679. doi: 10.1002/cphc. 201900006

Malär, A. A., Smith-Penzel, S., Camenisch, G. M., Wiegand, T., Samoson, A., Bockmann, A., et al. (2019). Quantifying proton NMR coherent linewidth in proteins under fast MAS conditions: a second moment approach. Phys. Chem. Chem. Phys. 21, 18850-18865. doi: 10.1039/c9cp03414e

Morris, G. A., and Freeman, R. (1979). Enhancement of nuclear magnetic resonance signals by polarization transfer. J. Am. Chem. Soc. 101, 760-762. doi: $10.1021 /$ ja00497a058

Mulder, F. A. A., Skrynnikov, N. R., Hon, B., Dahlquist, F. W., and Kay, L. E. (2001). Measurement of slow ( $\mu$ s-ms) time scale dynamics in protein side chains by $15 \mathrm{~N}$ relaxation dispersion NMR spectroscopy: application to Asn and Gln residues in a cavity mutant of T4 lysozyme. J. Am. Chem. Soc. 123, 967-975. doi: $10.1021 / \mathrm{ja} 003447 \mathrm{~g}$

Palmer, A. G., and Massi, F. (2006). Characterization of the dynamics of biomacromolecules using rotating-frame spin relaxation NMR spectroscopy. Chem. Rev. 106, 1700-1719. doi: 10.1021/cr0404287

Penzel, S., Oss, A., Org, M.-L., Samoson, A., Böckmann, A., Ernst, M., et al. (2019). Spinning faster: protein NMR at MAS frequencies up to $126 \mathrm{kHz}$. J. Biomol. NMR 73, 19-29. doi: 10.1007/s10858-018-0219-9

Raymond, A. C., Rideout, M. C., Staker, B., Hjerrild, K., and Burgin, A. B. (2004). Analysis of human tyrosyl-DNA phosphodiesterase I catalytic residues. J. Mol. Biol. 338, 895-906. doi: 10.1016/j.jmb.2004.03.013

Riek, R., and Eisenberg, D. S. (2016). The activities of amyloids from a structural perspective. Nature 539, 227-235. doi: 10.1038/nature20416

Sawaya, M. R., Sambashivan, S., Nelson, R., Ivanova, M. I., Sievers, S. A., Apostol, M. I., et al. (2007). Atomic structures of amyloid cross- $\beta$ spines reveal varied steric zippers. Nature 447, 453-457. doi: 10.1038/nature05695
Schanda, P., and Ernst, M. (2016). Studying dynamics by magic-angle spinning solid-state NMR spectroscopy: principles and applications to biomolecules. Prog. Nucl. Magn. Reson. Spectrosc. 96, 1-46. doi: 10.1016/j.pnmrs.2016.02.001

Schmidt, M., Wiese, S., Adak, V., Engler, J., Agarwal, S., Fritz, G., et al. (2019). Cryo-EM structure of a transthyretin-derived amyloid fibril from a patient with hereditary ATTR amyloidosis. Nat. Commun. 10:5008. doi: 10.1038/s41467019-13038-z

Smith, A. A. (2017). INFOS: spectrum fitting software for NMR analysis. J. Biomol. NMR 67, 77-94. doi: 10.1007/s10858-016-0085-2

Smith, A. A., Ravotti, F., Testori, E., Cadalbert, R., Ernst, M., Böckmann, A., et al. (2017). Partially-deuterated samples of HET-s(218-289) fibrils: assignment and deuterium isotope effect. J. Biomol. NMR 67, 109-119. doi: 10.1007/s10858016-0087-0

Smith, S. A., Levante, T. O., Meier, B. H., and Ernst, R. R. (1994). Computer simulations in magnetic resonance. An object-oriented programming approach. J. Magn. Reson. Ser. A 106, 75-105. doi: 10.1006/jmra.1994.1008

Smith-Penzel, S. (2019). Solid-State NMR Under Fast Magic-Angle Spinning (90-150 kHz) for Biological Applications. Zürich: ETH Zürich.

Sørensen, O. W., and Ernst, R. R. (1983). Elimination of spectral distortion in polarization transfer experiments. Improvements and comparison of techniques. J. Magn. Reson. 51, 477-489. doi: 10.1016/0022-2364(83)90300-1

Stephens, P. J., Devlin, F. J., Chabalowski, C. F., and Frisch, M. J. (1994). Ab initio calculation of vibrational absorption and circular dichroism spectra using density functional force fields. J. Phys. Chem. 98, 11623-11627. doi: 10.1021/ j100096a001

Sternberg, U., Witter, R., Kuprov, I., Lamley, J. M., Oss, A., Lewandowski, J. R., et al. (2018). 1H line width dependence on MAS speed in solid state NMR comparison of experiment and simulation. J. Magn. Reson. 291, 32-39. doi: 10.1016/j.jmr.2018.04.003

Stevens, T., Fogh, R., Boucher, W., Higman, V., Eisenmenger, F., Bardiaux, B., et al. (2011). A software framework for analysing solid-state MAS NMR data. J. Biomol. NMR 51, 437-447. doi: 10.1007/s10858-011-9569-2

Stöppler, D., Macpherson, A., Smith-Penzel, S., Basse, N., Lecomte, F., Deboves, $\mathrm{H}$., et al. (2018). Insight into small molecule binding to the neonatal Fc receptor by X-ray crystallography and $100 \mathrm{kHz}$ magic-angle-spinning NMR. PLoS Biol. 16:e2006192. doi: 10.1371/journal.pbio.2006192

Talavera, D., Robertson, D. L., and Lovell, S. C. (2011). Characterization of proteinprotein interaction interfaces from a single species. PLoS One 6:e21053. doi: 10.1371/journal.pone.0021053

Thomas, F., Niitsu, A., Oregioni, A., Bartlett, G. J., and Woolfson, D. N. (2017). Conformational dynamics of asparagine at coiled-coil interfaces. Biochemistry 56, 6544-6554. doi: 10.1021/acs.biochem.7b00848

Vallurupalli, P., Bouvignies, G., and Kay, L. E. (2012). Studying "invisible" excited protein states in slow exchange with a major state conformation. J. Am. Chem. Soc. 134, 8148-8161. doi: 10.1021/ja3001419

Van Melckebeke, H., Wasmer, C., Lange, A., Ab, E., Loquet, A., Böckmann, A., et al. (2010). Atomic-resolution three-dimensional structure of HET-s(218289) amyloid fibrils by solid-state NMR spectroscopy. J. Am. Chem. Soc. 132, 13765-13775. doi: 10.1021/ja104213j

Vance, C. K., Kang, Y. M., and Miller, A.-F. (1997). Selective 15N labeling and direct observation by NMR of the active-site glutamine of Fe-containing superoxide dismutase. J. Biomol. NMR 9, 201-206. doi: 10.1023/A:1018662421878

Vasa, S. K., Singh, H., Grohe, K., and Linser, R. (2019). Assessment of a large enzyme-drug complex by proton-detected solid-state NMR spectroscopy without deuteration. Angew. Chem. Int. Ed. Engl. 58, 5758-5762. doi: 10.1002/ anie. 201811714

Vernet, T., Tessier, D. C., Chatellier, J., Plouffe, C., Lee, T. S., Thomas, D. Y., et al. (1995). Structural and functional roles of asparagine 175 in the cysteine protease papain. J. Biol. Chem. 270, 16645-16652. doi: 10.1074/jbc.270.28. 16645

Vranken, W. F., Boucher, W., Stevens, T. J., Fogh, R. H., Pajon, A., Llinas, M., et al. (2005). The CCPN data model for NMR spectroscopy: development of a software pipeline. Proteins 59, 687-696. doi: 10.1002/prot.20449

Wagner, G., Pardi, A., and Wuethrich, K. (1983). Hydrogen bond length and proton NMR chemical shifts in proteins. J. Am. Chem. Soc. 105, 5948-5949. doi: $10.1021 /$ ja00356a056

Wälti, M. A., Ravotti, F., Arai, H., Glabe, C. G., Wall, J. S., Böckmann, A., et al. (2016). Atomic-resolution structure of a disease-relevant $A \beta(1-42)$ amyloid 
fibril. Proc. Natl. Acad. Sci. U.S.A. 113, E4976-E4984. doi: 10.1073/pnas. 1600749113

Wan, W., and Stubbs, G. (2014). Fungal prion HET-s as a model for structural complexity and self-propagation in prions. Proc. Natl. Acad. Sci. U.S.A. 111, 5201-5206. doi: 10.1073/pnas.1322933111

Wasmer, C., Lange, A., Van Melckebeke, H., Siemer, A. B., Riek, R., and Meier, B. H. (2008). Amyloid fibrils of the HET-s(218-289) prion form a $\beta$ solenoid with a triangular hydrophobic core. Science 319, 1523-1526. doi: 10.1126/science. 1151839

Weigend, F., and Ahlrichs, R. (2005). Balanced basis sets of split valence, triple zeta valence and quadruple zeta valence quality for $\mathrm{H}$ to $\mathrm{Rn}$ : design and assessment of accuracy. Phys. Chem. Chem. Phys. 7, 3297-3305. doi: 10.1039/b508541a

Wiegand, T. (2020). A solid-state NMR tool box for the investigation of ATPfueled protein engines. Prog. Nucl. Magn. Reson. Spectrosc. 117, 1-32. doi: 10.1016/j.pnmrs.2020.02.001

Wiegand, T., Cadalbert, R., Lacabanne, D., Timmins, J., Terradot, L., Bockmann, A., et al. (2019). The conformational changes coupling ATP hydrolysis and translocation in a bacterial DnaB helicase. Nat. Commun. 10:31. doi: 10.1038/ s41467-018-07968-3

Wiegand, T., Schledorn, M., Malär, A. A., Cadalbert, R., Däpp, A., Terradot, L., et al. (2020). Nucleotide binding modes in a motor protein revealed by $31 \mathrm{P}-$ and $1 \mathrm{H}-$ detected MAS solid-state NMR. ChemBioChem 21, 324-330. doi: 10.1002/cbic. 201900439
Worth, C. L., and Blundell, T. L. (2010). On the evolutionary conservation of hydrogen bonds made by buried polar amino acids: the hidden joists, braces and trusses of protein architecture. BMC Evol. Biol. 10:161. doi: 10.1186/14712148-10-161

Wu, H., Saltzberg, D. J., Kratochvil, H. T., Jo, H., Sali, A., and DeGrado, W. F. (2019). Glutamine side chain $13 \mathrm{C}-18 \mathrm{O}$ as a nonperturbative IR probe of amyloid fibril hydration and assembly. J. Am. Chem. Soc. 141, 7320-7326. doi: 10.1021/jacs.9b00577

Zorin, V. E., Brown, S. P., and Hodgkinson, P. (2006). Origins of linewidth in H1 magic-angle spinning NMR. J. Chem. Phys. 125:144508. doi: 10.1063/1.235 7602

Conflict of Interest: The authors declare that the research was conducted in the absence of any commercial or financial relationships that could be construed as a potential conflict of interest.

Copyright (c) 2020 Wiegand, Malär, Cadalbert, Ernst, Böckmann and Meier. This is an open-access article distributed under the terms of the Creative Commons Attribution License (CC BY). The use, distribution or reproduction in other forums is permitted, provided the original author(s) and the copyright owner(s) are credited and that the original publication in this journal is cited, in accordance with accepted academic practice. No use, distribution or reproduction is permitted which does not comply with these terms. 